\title{
BEBERAPA PEMIKIRAN TENTANG SISTEM DAN KERANGKA REFERENSI KOORDINAT UNTUK DKI JAKARTA
}

\author{
Hasanuddin Z. Abidin \\ Jurusan Teknik Geodesi, Institut Teknologi Bandung \\ J1. Ganesha 10, Bandung 40132 \\ e-mail : hzabidin@gd.itb.ac.id
}

\begin{abstract}
ABSTRAK
Pembangunan fisik di wilayah Jakarta berjalan relatif cukup cepat. Untuk menunjang proses pembangunan secara berkelanjutan diperlukan peta dasar kota maupun Sistem Informasi Geografis (SIG) yang lengkap, baik, dan up-to-date. Untuk penyiapan dan pembangunan suatu peta dasar serta SIG wilayah Jakarta yang andal, maka keberadaan suatu sistem dan kerangka referensi koordinat yang baik untuk seluruh wilayah Jakarta adalah suatu keharusan. Makalah ini akan mendiskusikan beberapa permasalahan dari sistem dan kerangka referensi koordinat Jakarta serta memberikan beberapa pemikiran untuk meningkatkan kualitas dari sistem dan referensi koordinat Jakarta. Makalah akan ditutup dengan beberapa kesimpulan dan saran.
\end{abstract}

\section{PENDAHULUAN}

Jakarta adalah metropolitan dan ibukota negara yang proses pembangunannya berjalan relatif cukup cepat. Untuk menunjang proses pembangunan secara berkelanjutan diperlukan peta dasar kota maupun Sistem Informasi Geografis (SIG) yang lengkap, baik, dan up-to-date. Untuk penyiapan dan pembangunan suatu peta dasar serta SIG wilayah Jakarta yang andal, maka keberadaan suatu sistem dan kerangka referensi koordinat yang baik untuk seluruh wilayah Jakarta adalah suatu keharusan.

Dengan adanya suatu sistem dan kerangka referensi koordinat yang baik dan menyeluruh untuk seluruh wilayah Jakarta, maka setiap tahapan proses pembangunan yang memerlukan jasa pengukuran dan pemetaan serta informasi spasial, akan dapat dilayani secara efektif dan efisien. Begitu juga proses mitigasi bencana kebumian, seperti banjir dan penurunan tanah, juga akan dapat terbantu.

Proses pemetaan dan pembuatan dasar di wilayah Jakarta sendiri pada prinsipnya sudah dimulai sejak zaman Belanda. Sejak jaman kemerdekaan sampai sekarang, pembuatan peta dasar wilayah Jakarta dilakukan oleh beberapa instansi sekaligus untuk keperluan yang berbeda-beda, seperti yang ditunjukkan pada Tabel 1. Dari fakta yang ditunjukkan pada Tabel 1 dapat disimpulkan bahwa mengingat adanya beberapa instansi yang terlibat dalam proses pembuatan peta dasar di wilayah Jakarta, maka dapat diperkirakan bahwa sistem dan kerangka referensi koordinat yang ada di wilayah Jakarta bukanlah sistem dan kerangka yang tunggal dan homogen. Adanya sistem dan kerangka referensi koordinat yang berbeda-beda dengan tingkat ketelitian yang tidak homogen nampaknya bukanlah suatu hal yang mustahil terjadi di wilayah Jakarta. Hal ini akhirnya akan memberikan dampak negatif terhadap proses pembangunan yang bersandar pada penggunaan sistem dan kerangka referensi koordinat tersebut.

Tulisan ini akan mencoba memberikan beberapa sumbangan pemikiran berkaitan dengan sistem dan referensi koordinat di wilayah Jakarta tersebut. Untuk memberikan pemahaman yang lebih baik, penjelasan singkat tentang sistem dan kerangka koordinat akan diberikan pada awal tulisan. 
Tabel 1. Sejarah pembuatan peta dasar di wilayah Jakarta [DPPT, 2000].

\begin{tabular}{|c|c|c|}
\hline Periode & $\begin{array}{c}\begin{array}{c}\text { Instansi pembuat } \\
\text { peta dasar }\end{array} \\
\end{array}$ & Keperluan \\
\hline $\begin{array}{c}\text { sampai } \\
1970\end{array}$ & $\begin{array}{l}\text { - Jawatan Pekerjaan Umum } \\
\text { - Kantor Kadaster }\end{array}$ & $\begin{array}{l}\text { - Pembangunan sarana \& prasarana } \\
\text { - Pendaftaran tanah }\end{array}$ \\
\hline 1971-1974 & $\begin{array}{l}\text { - Dinas Tata Kota (DTK) } \\
\text { - Direktorat Agraria } \\
\text { - Kantor Ipeda }\end{array}$ & $\begin{array}{l}\text { - Perencanaan kota untuk pemba- } \\
\text { ngunan sarana \& prasarana fisik } \\
\text { - Pendaftaran tanah } \\
\text { - Pajak atas tanah. }\end{array}$ \\
\hline $\begin{array}{c}\text { 1975- } \\
\text { sekarang }\end{array}$ & $\begin{array}{l}\text { - Dinas Tata Kota } \\
\text { - Dinas Pemetaan dan } \\
\text { Pengukuran Tanah (DPPT) } \\
\text { - Kanwil BPN } \\
\text { - Kanwil PBB }\end{array}$ & $\begin{array}{l}\text { - Perencanaan kota untuk pemba- } \\
\text { ngunan sarana \& prasarana fisik } \\
\text { - Pemetaan dasar } \\
\text { - Pendaftaran tanah } \\
\text { - Pajak atas tanah. }\end{array}$ \\
\hline
\end{tabular}

\section{SISTEM REFERENSI KOORDINAT}

Posisi suatu titik dapat dinyatakan secara kuantitatif maupun kualitatif. Secara kuantitatif posisi suatu titik dinyatakan dengan koordinat, baik dalam ruang satu, dua, tiga, maupun empat dimensi (1D, 2D, 3D, maupun 4D). Perlu dicatat di sini bahwa koordinat tidak hanya memberikan deskripsi kuantitatif tentang posisi, tapi juga pergerakan (trayektori) suatu titik seandainya titik yang bersangkutan bergerak. Untuk menjamin adanya konsistensi dan standarisasi, perlu ada suatu sistem dalam menyatakan koordinat. Sistem ini disebut sistem referensi koordinat, atau secara singkat sistem koordinat, dan realisasinya umum dinamakan kerangka referensi koordinat.

\subsection{Pengertian Sistem Referensi Koordinat}

Sistem referensi koordinat adalah sistem (termasuk teori, konsep, deskripsi fisis dan geometris, serta standar dan parameter) yang digunakan dalam pendefinisian koordinat dari suatu atau beberapa titik dalam ruang. Dalam bidang geodesi dan geomatika, posisi suatu titik biasanya dinyatakan dengan koordinat (dua-dimensi atau tiga-dimensi) yang mengacu pada suatu sistem koordinat tertentu. Sistem koordinat itu sendiri didefinisikan dengan menspesfikasi tiga parameter berikut, yaitu :

- lokasi titik nol dari sistem koordinat,

- orientasi dari sumbu-sumbu koordinat, dan

- besaran (kartesian, curvilinear) yang digunakan untuk mendefiniskan posisi suatu titik dalam sistem koordinat tersebut.

Setiap parameter dari sistem koordinat tersebut dapat dispesifikasikan lebih lanjut, dan tergantung dari spesifikasi parameter yang digunakan maka dikenal beberapa jenis sistem koordinat. Dalam penentuan posisi suatu titik di permukaan bumi, titik nol dari sistem koordinat yang digunakan dapat berlokasi di titik pusat massa bumi (sistem koordinat geosentrik), maupun di salah satu titik di permukaan bumi (sistem koordinat toposentrik). Kedua sistem koordinat diilustrasikan pada Gambar 1 dan 2 berikut.

Sistem koordinat geosentrik banyak digunakan oleh metode-metode penentuan posisi ekstra-terestris yang mengguna-kan satelit dan benda-benda langit lainnya, baik untuk menentukan posisi titik-titik di permukaan Bumi maupun posisi satelit. Sedangkan sistem koordinat toposentrik banyak digunakan oleh metode-metode penentuan posisi terestris. Dilihat dari orientasi sumbunya, ada sistem koordinat yang sumbu-sumbunya ikut berotasi dengan bumi (terikat bumi) dan ada yang tidak (terikat langit). Sistem koordinat yang terikat bumi umumnya digunakan untuk menyatakan posisi titik-titik yang berada di bumi, dan sistem yang terikat langit umumnya digunakan untuk menyatakan posisi titik dan obyek di angkasa, seperti satelit dan benda-benda langit. Dilihat dari besaran koordinat yang digunakan, posisi suatu titik dalam sistem koordinat 
ada yang dinyatakan dengan besaran-besaran jarak seperti sistem koordinat Kartesian, dan ada yang dengan besaran-besaran sudut dan jarak seperti sistem pada sistem koordinat ellipsoid atau geodetik, seperti yang ditunjukkan pada Gambar 1.

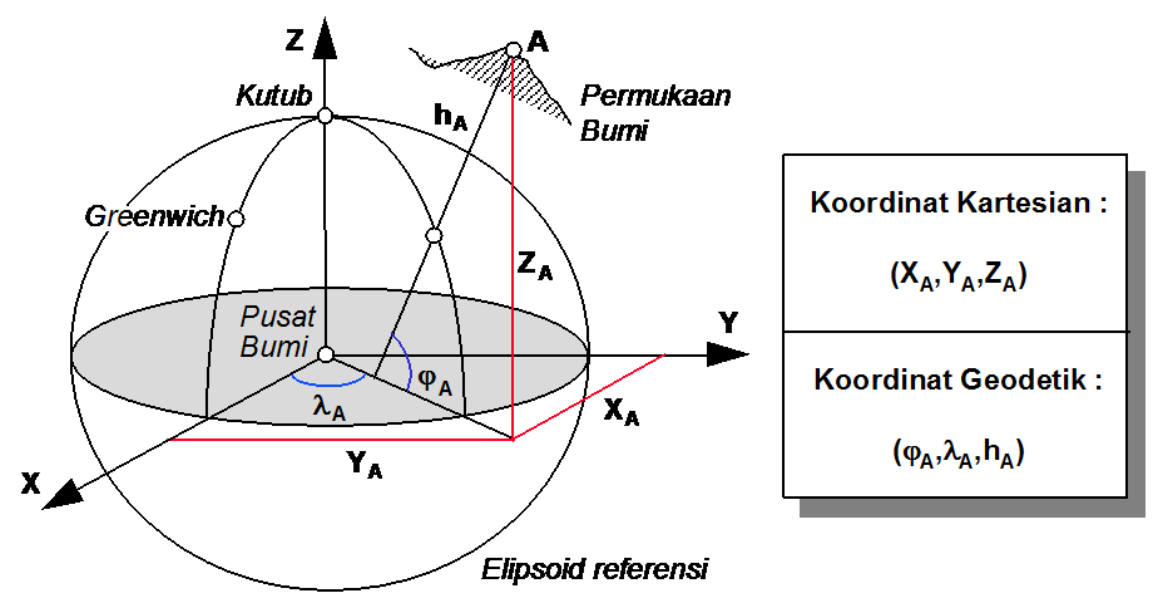

Gambar 1. Posisi titik dalam sistem koordinat geosentrik (kartesian dan geodetik).

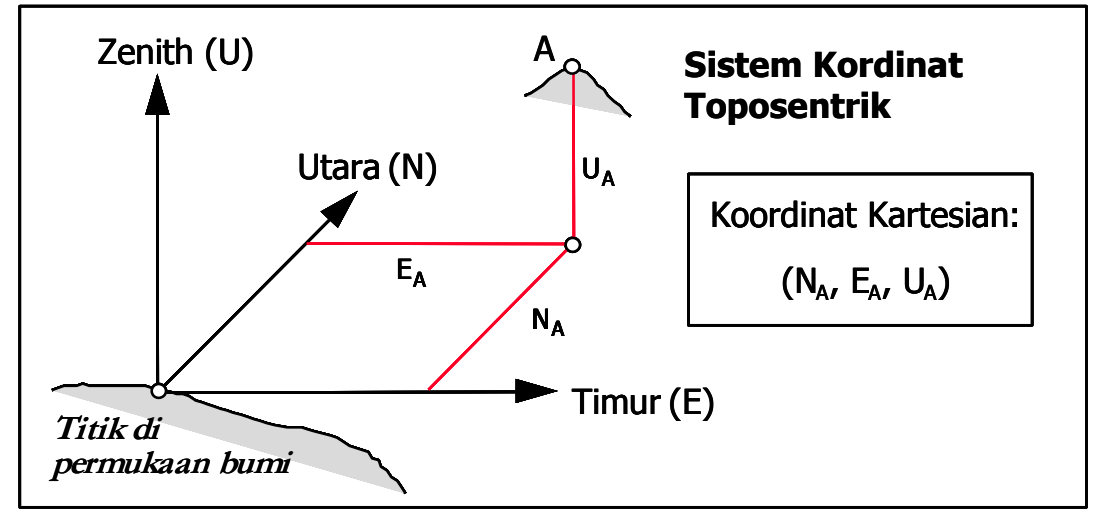

Gambar 2. Posisi titik dalam sistem koordinat toposentrik.

\subsection{Sistem Referensi Koordinat Jakarta}

Kalau kita pelajari sejarah pemetaan di wilayah Jakarta, seperti yang diberikan di DPPT (2000), sistem referensi koordinat yang digunakan, baik itu Sistem-32 maupun Sistem80, pada dasarnya adalah sistem kartesian dua-dimensi yang sifatnya lokal. Dalam hal ini wilayah Jakarta dianggap bidang datar, dan dalam pendefinisian koordinatnya datum geodetik tidak didefinisikan. Titik nol dari Sistem-32 berada di Pejompongan, dan titik nol Sistem-80 berada di sekitar Monas. Sedangka arah sumbu-X dan sumbu-Y nya masing-masing ke arah Timur dan Utara dari peta yang bersangkutan.

Kalau kita simak secara seksama, penggunaan sistem-sistem referensi koordinat yang sifatnya lokal ini untuk aplikasi tertentu sudah cukup memadai. Tapi dengan berkembangnya aplikasi survei dan pemetaan di wilayah Jakarta, terutama yang terkait dengan pembangunan SIG, pemakaian sistem referensi lokal cukup merepotkan, terutama kalau kita ingin mengintegrasikan beragam informasi spasial secara terpadu. Apalagi kalau kita mengingat bahwa proses pembangunan di wilayah Jakarta sangat terkait dengan proses pembangunan di wilayah yang melingkupi Jakarta, yaitu Tanggerang, Bogor, Bekasi, dan Depok, yang pada prinsipnya tidak menggunakan sistem referensi koordinat yang digunakan di Jakarta. 
Oleh sebab itu sebaiknya sistem referensi koordinat yang digunakan di Jakarta adalah suatu sistem referensi yang sifatnya nasional, seperti yang diilustrasikan pada Tabel 2 berikut. Dalam hal ini, untuk sistem koordinatnya sebaiknya menggunakan sistem TM-3 (Traverse Mercator dengan lebar zone $3^{0}$ ) yang saat ini digunakan secara nasional oleh BPN untuk proses pendaftaran dan pemetaan tanah di wilayah Indonesia. Disamping itu datum geodetik yang digunakan juga sebaiknya ditentukan, yang dalam hal ini sebaiknya adalah Datum Geodesi Nasional (DGN) 1995, suatu datum yang telah ditetapkan oleh BAKOSURTANAL sebagai datum nasional untuk keperluan survei pemetaan dan penentuan posisi.

Tabel 2. Sistem referensi koordinat Jakarta

\begin{tabular}{|l|c|c|}
\hline & Sistem Referensi Koordinat Jakarta \\
\hline & KONDISI SEKARANG & SEBAIKNYA \\
\hline Sistem Koordinat 2D & $\begin{array}{c}\text { Kartesian 2D lokal } \\
\text { (Sistem-32, Sistem-80) }\end{array}$ & $\begin{array}{c}\text { TM-3 (sistem nasional yang } \\
\text { digunakan BPN) }\end{array}$ \\
\hline Datum Geodetik & Tidak ditentukan & DGN-95 (Nasional) \\
\hline
\end{tabular}

\section{KERANGKA REFERENSI KOORDINAT}

\subsection{Pengertian Kerangka Referensi Koordinat}

Kerangka referensi koordinat adalah realisasi praktis dari suatu sistem referensi koordinat, sehingga sistem tersebut dapat digunakan untuk pendeskripsian secara kuantitatif posisi dan pergerakan titik-titik, baik di permukaan bumi (kerangka terestris) ataupun di luar bumi (kerangka selestia atau ekstra-terestris). Kerangka referensi biasanya direalisasikan dengan melakukan pengamatan-pengamatan geodetik, dan umumnya direpresentasikan dengan menggunakan suatu set koordinat dari sekumpulan titik.

Kerangka referensi koordinat yang di lapangan umumnya direpresentasikan dengan tugu-tugu yang koordinatnya sudah diketahui, umumnya berfungsi sebagai titik-titik kontrol atau titik-titik ikat untuk keperluan pengukuran dan pemetaan.

\subsection{Kerangka Referensi Koordinat Jakarta}

Sampai saat ini pada prinsipnya ada beberapa kerangka referensi koordinat yang telah dibangun di wilayah Jakarta, yaitu :

1. Kerangka Sistem-32; yang ditentukan dengan pengamatan triangulasi pada tahun 1932. Kerangka ini digunakan oleh Dinas Tata Kota (DTK) DKI Jakarta, dan kerangka ini dirapatkan dengan menggunakan pengukuran terestris metode poligon.

2. Kerangka Sistem-72; yang berbasiskan pada pemotretan udara pada tahun 1972 yang dilaksanakan oleh Laboratorium Fotogrametri DKI Jakarta.

3. Kerangka Sistem-80; yang merupakan integrasi antara kerangka-kerangka Sistem-32 dan Sistem-72. Kerangka ini digunakan oleh Dinas Pemetaan dan Pengukuran Tanah (DPPT) DKI Jakarta.

4. Kerangka GPS BPN Orde-2; yang merupakan kerangka titik-titik kontrol yang ditentukan oleh BPN secara nasional dengan pengamatan satelit GPS untuk keperluan pengukuran dan pendaftaran tanah. Dalam kerangka ini titik-titik kontrol GPS berjarak sekitar 5-10 km antar sesamanya. Untuk wilayah Jakarta terdapat sekitar 16 titik kontrol Orde-2 ini, yang diukur pada tahun anggaran $1994 / 95$.

5. Kerangka GPS BPN Orde-3; yang merupakan kerangka titik-titik kontrol GPS yang merupakan perapatan kerangka GPS Orde-2. Dalam kerangka ini titik-titik kontrol GPS berjarak sekitar 1-2 km antar sesamanya, dan untuk wilayah 
Jakarta terdapat sekitar 600 titik kontrol Orde-3 ini yang dibangun pada periode 1996/97 dan 1997/98.

6. Kerangka Terestris BPN Orde-4; yang merupakan kerangka titik-titik kontrol yang merupakan perapatan dari kerangka GPS Orde-4. Dalam hal ini perapatan dilakukan dengan metode poligon dan jarak antar titik adalah sekitar $150 \mathrm{~m}$. Penulis tidak mengetahui jumlah titik-titik kontrol Orde-4 di wilayah Jakarta sampai saat ini

Kalau kita lihat dari daftar kerangka koordinat yang ada di atas, sebenarnya jumlah titik-titik kontrol yang ada di wilayah Jakarta sudah cukup memadai untuk menunjang pekerjaan-pekerjaan pengukuran dan pemetaan di wilayah Jakarta. Hanya problem utamanya di sini adalah bahwa kerangka-kerangka tersebut mempunyai spektrum dan karakteristik ketelitian koordinat yang variatif dan tidak homogen.

Karena untuk pekerjaan-pekerjaan pengukuran sebaiknya kerangka koordinat yang digunakan adalah suatu kerangka yang tunggal dan relatif homogen secara ketelitian, maka sebaiknya kerangka koordinat yang digunakan untuk wilayah Jakarta adalah suatu kerangka kerangka koordinat yang bersifat nasional dengan datum geodetik yang jelas terdefinisi, seperti yang ditunjukkan oleh Tabel 3.

Tabel 3. Kerangka referensi koordinat Jakarta (status 2000)

\begin{tabular}{|c|c|c|c|}
\hline & \multicolumn{3}{|c|}{ Kerangka Referensi Koordinat Jakarta } \\
\hline $\begin{array}{c}\text { Kerangka } \\
\text { Koordinat }\end{array}$ & $\bullet \begin{array}{l}\text { KONDISI SEKARANG } \\
\text { triangulasitik-titik }\end{array}$ & $\begin{array}{l}\text { SEBAIKNYA ditambah } \\
\text { Kerangka titik-titik poligon } \\
\text { (Sistem-32 dan Sistem-80) }\end{array}$ & $\begin{array}{l}\text { Berbasiskan pada kerangka } \\
\text { GPS Orde-2 dan Orde-3 yang } \\
\text { dibangun oleh BPN, } \\
\text { ditambah } \\
\text { Kerangka Orde-4 (Poligon) } \\
\text { yang dibangun oleh BPN. }\end{array}$ \\
\hline $\begin{array}{c}\text { Datum } \\
\text { Geodetik }\end{array}$ & Tidak ditentukan & DGN-95 (Nasional) \\
\hline
\end{tabular}

Dalam hal ini karena kerangka koordinat yang bersifat nasional di wilayah Jakarta adalah kerangka GPS BPN Orde-2 dan Orde-3, serta kerangka BPN Orde-4 maka sebaiknya kerangka koordinat Jakarta juga berbasiskan pada kerangka-kerangka koordinat nasional tersebut. Meskipun begitu kerangka-kerangka yang sudah ada, apakah itu kerangka Sistem-32 maupun kerangka Sistem-80 sebaiknya tidak dibuang begitu saja. Sebaiknya kedua kerangka terestris ini ditingkatkan kualitasnya sedemikian rupa sehingga dapat digabungkan dengan kerangka-kerangka nasional yang dibangun BPN dengan menggunakan teknologi GPS [Abidin, 2000], seperti yang diilustrasikan pada Gambar 3 berikut ini. Disamping itu kalau diperlukan, maka pengukuranpengukuran titik kontrol tambahan yang baru dapat dilakukan. Pengukuran titik-titik kontrol tambahan ini, disamping untuk mendapatkan distribusi titik kontrol yang lebih baik, juga dapat digunakan untuk menentukan parameter transformasi dari kerangkakerangka lokal (Sistem-32, Sistem-80) ke kerangka yang bersifat nasional.

Sebagai contoh, untuk kasus DTK yang menggunakan titik-titik triangulasi 1932 sebagai titik-titik kontrol primernya, maka untuk masa mendatang sebaiknya DTK menggunakan suatu kerangka koordinat primer yang baru, yang mensinergikan kerangka GPS BPN Orde-2 dan Kerangka Primer S-32 yang ada. Menurut hemat penulis kerangka koordinat primer wilayah Jakarta cukup terdiri atas 19 titik kontrol yang distribusinya ditunjukkan pada Gambar 4. 


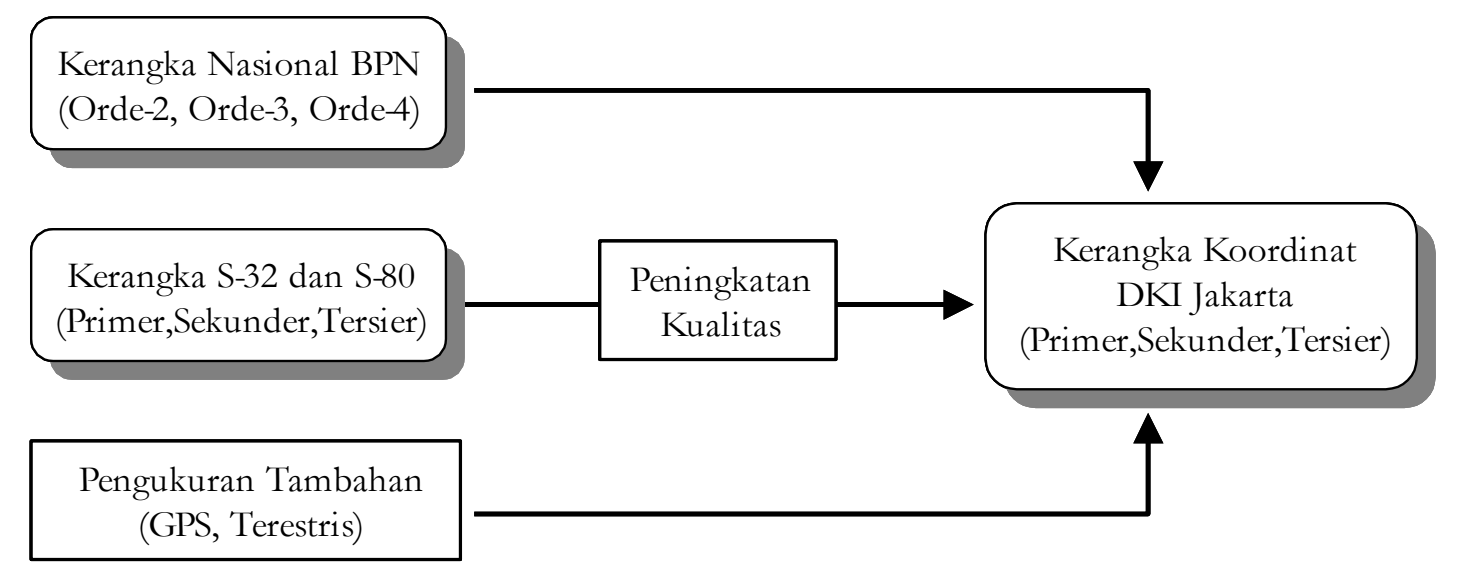

Gambar 3. Pembangunan kerangka koordinat Jakarta yang definitif.

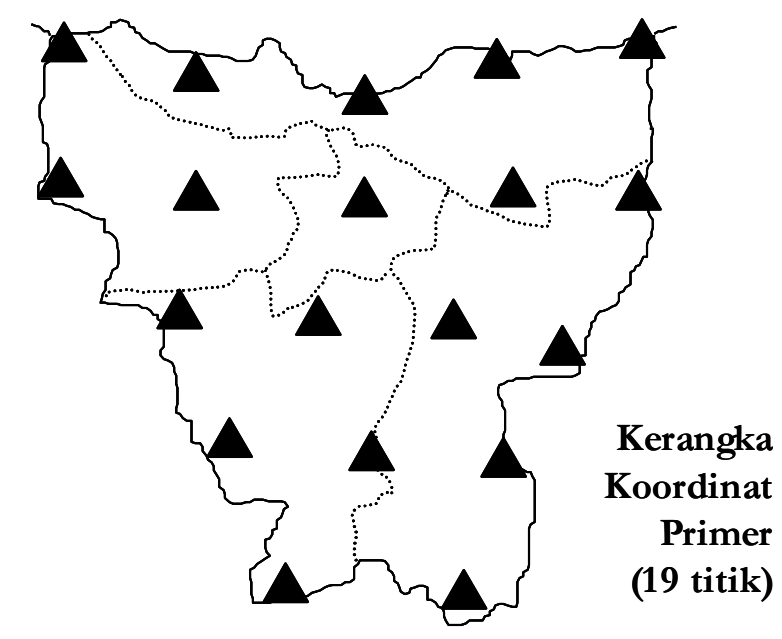

Gambar 4. Idealisasi Kerangka Koordinat Primer Jakarta

Realisasi dari ke 19 titik kerangka primer ini sebaiknya dilakukan dengan mengintegrasikan titik-titik kontrol GPS BPN Orde-2 yang masih ada tugunya di wilayah Jakarta, titik-titik kontrol primer sistem-32 yang masih ada tugunya di lapangan, serta pengukuran yang baru dengan survei GPS [Abidin, 2000; Abidin et al., 1995] seandainya diperlukan, seperti yang diilustrasikan pada Gambar 5 berikut.

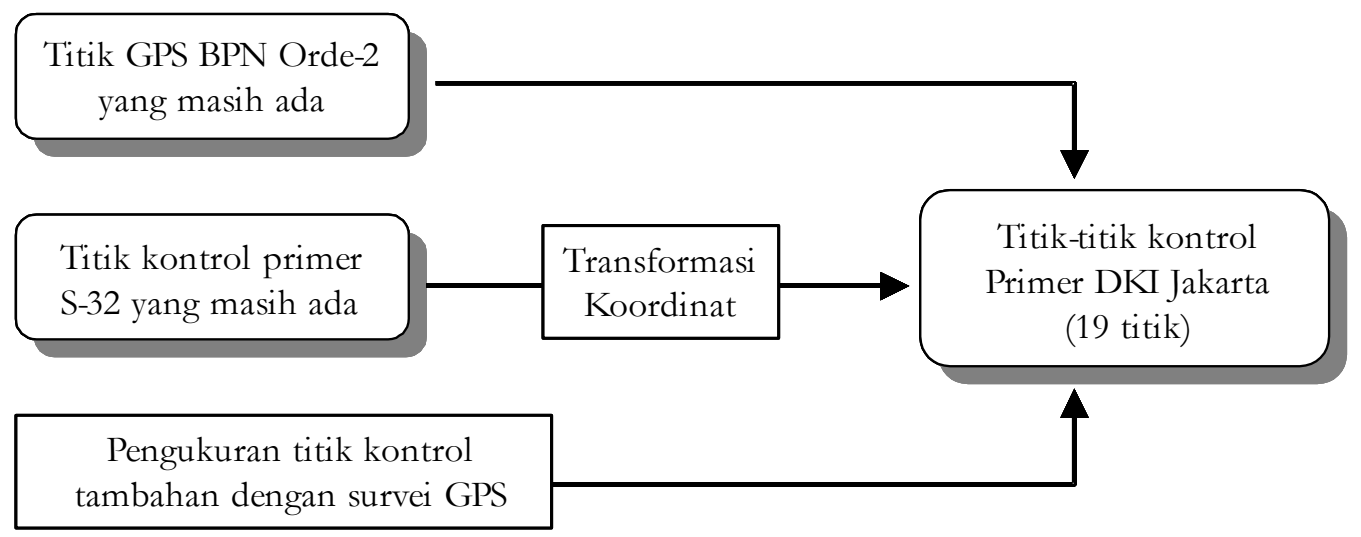

Gambar 5. Mekanisme Realisasi Kerangka Koordinat Primer Jakarta 
Dari informasi yang penulis peroleh, pada saat ini ada sekitar 16 titik GPS BPN Orde-2 yang masih ada tugu (monumen) nya di lapangan. Disamping itu ada 3 titik triangulasi yang merupakan titik kontrol primer sistem-32 yang masih ada tugunya di lapangan. Dari data ini nampaknya pengukuran titik kontrol tambahan dengan survei GPS tidak perlu terlalu banyak dilakukan, dan seandainyapun dilakukan terutama untuk mendapatkan distribusi titik kontrol yang baik seperti digambarkan pada Gambar 4 sebelumnya, dan juga untuk memperoleh parameter transformasi koordinat dari sistem32 ke sistem nasional (TM-3, datum DGN95) yang dalam hal ini diwakili oleh kerangka GPS BPN Orde-2.

Dari 19 titik kontrol primer ini selanjutnya diturunkan kerangka titik kontrol sekunder. Mengingat pada saat ini di wilayah Jakarta ada sekitar 660 titik GPS BPN Orde-3 dengan jarak antar titik sekitar 1-2 km, maka sebaiknya kerangka titik kontrol sekunder Jakartapun memanfaatkan seoptimal mungkin kerangka titik kontrol yang relatif sudah cukup rapat tersebut. Secara idealnya kalau kita menempatkan titik-titik kontrol sekunder seperti yang divisualisasikan pada Gambar 6, maka untuk seluruh Jakarta diperkirakan akan terdapat sekitar 500 sampai 600 titik kontrol sekunder.

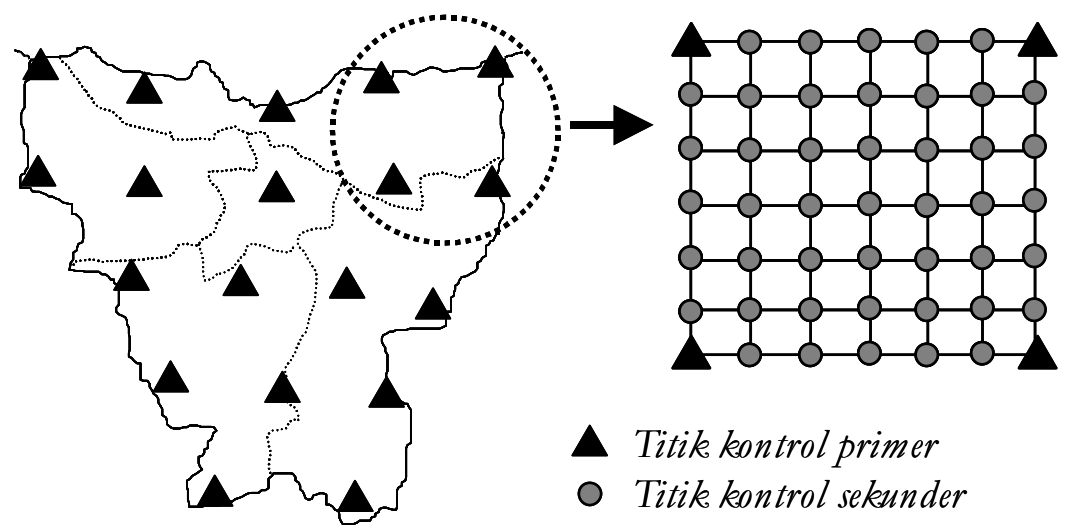

Gambar 6. Idealisasi Kerangka Koordinat Sekunder Jakarta

Kalau kita asumsikan bahwa dari 660 titik GPS BPN Orde-3 sebagian besar tugunya masih ada di lapangan, maka bersama-sama dengan titik-titik kontrol Sistem-32 yang masih ada di lapangan, nampaknya tidak terlalu sulit untuk merealisasikan sekitar 500 sampai 600 titik kontrol sekunder dengan kualitas yang baik dan homogen untuk seluruh Jakarta. Dalam hal ini pengukuran titik-titik kontrol yang baru dengan metode survei GPS diperlukan untuk mendapatkan distribusi titik kontrol sekunder yang lebih baik, serta untuk menentukan parameter transformasi antara kerangka sekunder sistem-32 dengan kerangka GPS BPN Orde-3 yang berada dalam sistem referensi nasional. Mekanisme realisasi kerangka koordinat sekunder ini diilustrasikan pada Gambar 7 .

Selanjutnya kerangka koordinat sekunder ini dirapatkan kembali untuk membangun kerangka koordinat tersier. Untuk keperluan pemetaan detail dan pekerjaan opname, titik-titik kontrol tersier ini secara umum akan merupakan titik kontrol yang paling banyak digunakan. Karena kerangka terestris BPN Orde-4 yang sedang dan akan dibangun oleh pihak BPN di wilayah Jakarta mempunyai spasi antar titik sekitar $150 \mathrm{~m}$, maka spasi titik kerangka koordinat tersier DKI Jakarta juga sebaiknya sekitar $150 \mathrm{~m}$, sehingga secara mudah kerangka BPN orde-4 ini diintegrasikan ke kerangka tersier DKI Jakarta. 


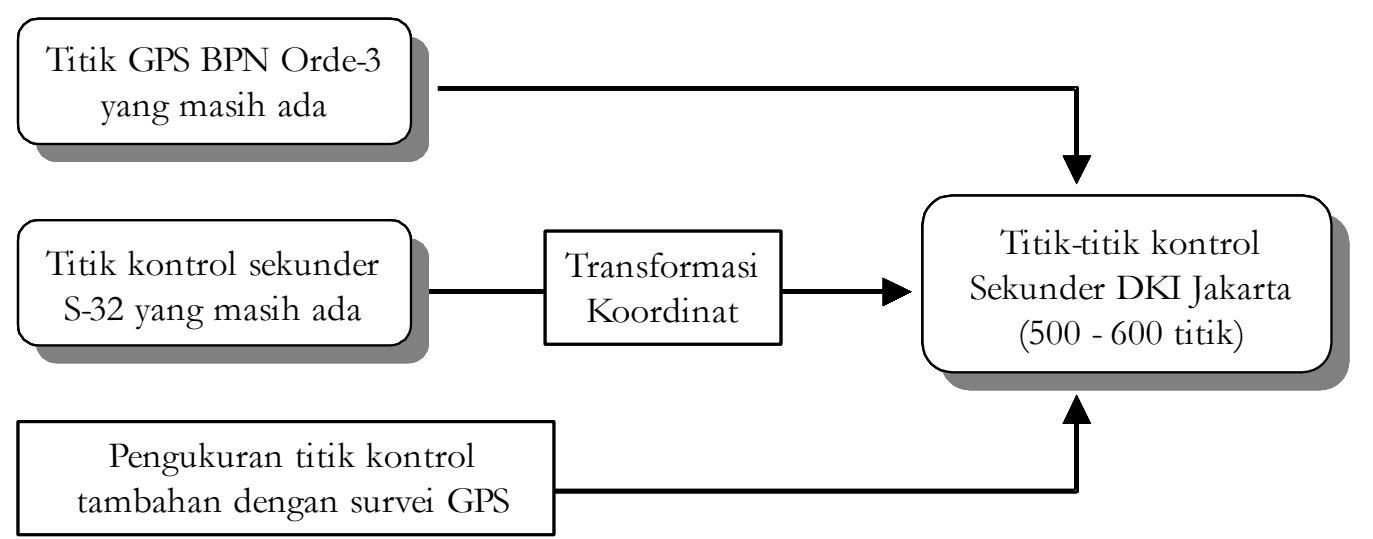

Gambar 7. Mekanisme Realisasi Kerangka Koordinat Sekunder Jakarta

Seperti halnya dalam pembangunan kerangka koordinat primer dan sekunder DKI Jakarta, dalam pembangunan kerangka koordinat tersier Jakarta pun, kerangka tersier sistem-32 yang sudah ada sebaiknya diintegrasikan dengan kerangka terestris BPN Orde-4 seperti yang diilustrasikan pada Gambar 8.

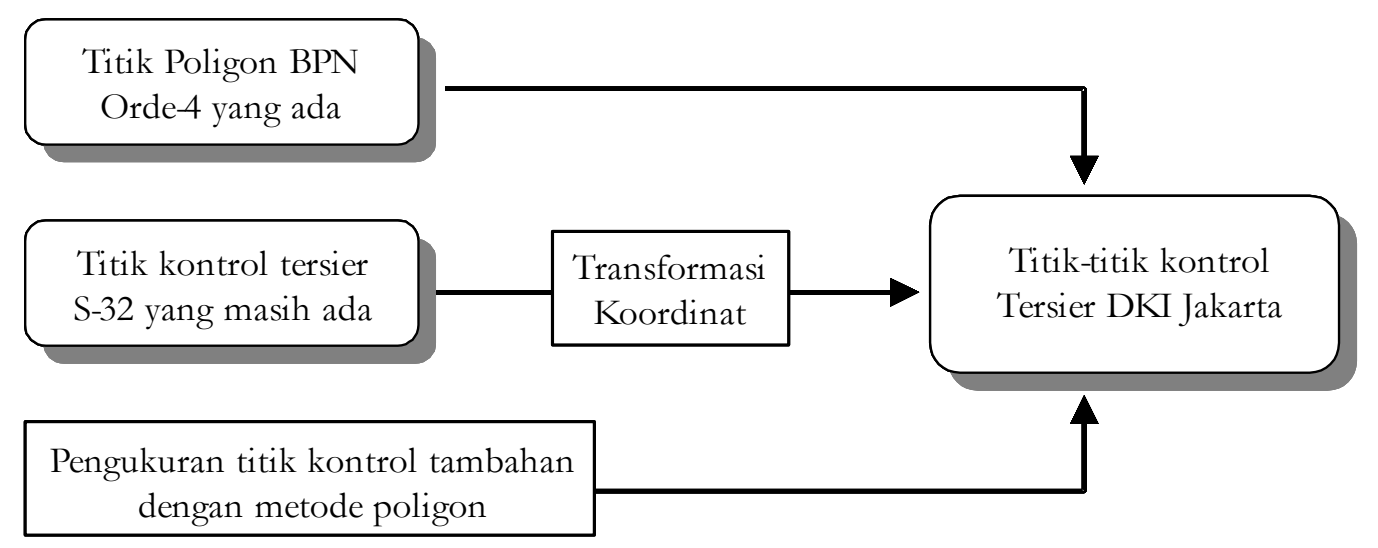

Gambar 8. Mekanisme Realisasi Kerangka Koordinat Tersier Jakarta

Dalam realisasi kerangka koordinat tersier DKI Jakarta ini, mengingat titik-titik poligon BPN Orde-4 di wilayah Jakarta belumlah komplit, maka pihak Dinas Tata Kota, disamping perlu mengintensifkan proses transformasi koordinat dari titik-titik kontrol tersier sistem-32 yang masih ada, juga nampaknya perlu mengantisipasi pengukuran titik-titik kontrol tersier tambahan dengan menggunakan metode poligon.

\section{KESIMPULAN DAN SARAN}

Dari pembahasan sebelumnya, ada beberapa hal yang perlu untuk disimpulkan dan disarankan, yaitu antara lain :

1. Sistem dan referensi koordinat DKI Jakarta sebaiknya mulai dinyatakan dalam suatu sistem dan kerangka yang bersifat nasional. Ini penting untuk mengantisipasi proses pembangunan di wilayah Jakarta, yang lajunya semakin cepat, dan juga kaitannya dengan pembangunan di wilayah-wilayah sekitarnya yang semakin erat.

2. Dalam penetapan suatu kerangka referensi koordinat yang definitif, baik itu kerangka primer, sekunder, maupun tersier; kerangka-kerangka koordinat yang sudah ada di wilayah Jakarta sebaiknya dimanfaatkan secara optimal, baik itu kerangka koordinat lokal sistem-32 dan sistem-80, maupun kerangka-kerangka 
koordinat yang bersifat nasional berupa kerangka GPS BPN Orde-2 dan Orde-3, serta kerangka Terestris BPN Orde-4.

3. Melihat jumlah titik-titik kontrol GPS BPN Orde-2 dan Orde-3 serta titik-titik kontrol Terestris BPN Orde-4 yang sudah cukup memadai di wilayah DKI Jakarta, beserta titik-titik kontrol lokal dalam Sistem-32 dan Sistem-80 yang sudah ada, baik itu titik-titik kontrol primer, sekunder, dan tersier, maka secara umum jumlah titiktitik kontrol yang tersedia sudah memadai untuk keperluan pekerjaan-pekerjaan pengukuran dan pemetaan di wilayah DKI Jakarta, meskipun memang masih ada variasi ketelitian dari titik-titik kontrol tersebut.

4. Oleh sebab itu untuk keperluan standarisasi dan konsistensi metodologi dan hasil pengukuran, penetapan suatu kerangka referensi yang definitif dan konsisten untuk seluruh wilayah DKI Jakarta perlu dilakukan sesegera mungkin. Mengingat jumlah titik kontrol yang telah ada dan juga teknologi penentuan posisi yang tersedia saat ini, penetapan ini bukanlah suatu hal yang sulit; meskipun memang masih diperlukan beberapa pengukuran titik-titik kontrol tambahan yang baru.

5. Pengukuran-pengukuran titik kontrol tambahan, baik dengan metode GPS (untuk kerangka primer dan sekunder) maupun metode poligon (untuk kerangka tersier), masih perlu dilakukan karena beberapa hal; yaitu untuk mendapatkan distribusi titik kontrol yang optimal dan merata, serta untuk menentukan parameter transformasi antara kerangka-kerangka lokal (Sistem-32, Sistem-80) dengan kerangka-kerangka nasional (GPS Orde-2, GPS Orde-3, Terestris Orde-4) yang telah dibangun oleh pihak BPN di wilayah DKI Jakarta.

6. Dalam penetapan sistem dan kerangka referensi koordinat di wilayah DKI Jakarta ini, koordinasi dan kerjasama antara instansi-instansi yang terkait (DTK, DPPT, BPN, BAKOSURTANAL) perlu dilakukan secara baik dan berkesinambungan. Keterlibatan pihak Universitas dalam memberikan arahan dan masukan yang bersifat teoritis akademik juga disarankan dalam rangka memperoleh hasil yang optimal, efektif, dan efisien.

7. Seandainya karena alasan finansial dan operasional, kerangka referensi koordinat DKI Jakarta masih lebih efisien untuk tetap dinyatakan dalam sistem lokal, seperti sistem-32, maka dalam hal ini yang boleh diasumsikan sebagai masa transisi, maka parameter transformasi antara kerangka lokal (primer, sekunder, dan tersier) tersebut dengan kerangka-kerangka yang bersifat nasional harus ditentukan secara baik untuk seluruh wilayah Jakarta. Dengan adanya sistem transformasi yang baik tersebut, maka pada prinsipnya kerangka koordinat DKI Jakarta akan dapat dibangun kembali dan diremajakan dengan menggunakan metode survei GPS dan juga metode pengukuran poligon yang diikatkan ke kerangka-kerangka nasional yang ada di wilayah Jakarta, baik itu titik-titik kontrol nasional yang dibangun BPN maupun BAKOSURTANAL (kalau ada).

Dalam pendekatan ini perlu ditekankan bahwa sebaiknya sistem transformasi digunakan terutama untuk mentransformasikan titik-titik kontrol yang sudah ada dalam sistem nasional, yaitu kerangka-kerangka GPS BPN Orde-2 dan Orde-3 serta Terestris BPN Orde-4, ke dalam sistem-32. Untuk titik-titik kontrol lokal yang ketelitiannya tidak diketahui atau diperkirakan tidak memenuhi syarat, sebaiknya sedikit demi sedikit mulai ditinggalkan. Hanya titik-titik kontrol lokal yang mempunyai tingkat ketelitian yang jelas dan memenuhi syarat saja yang sebaiknya diintegrasikan dengan titik-titik kontrol nasional yang dibangun oleh BPN di wilayah DKI Jakarta. 


\section{DAFTAR ACUAN}

Abidin, H.Z. (2000). Penentuan Posisi Dengan GPS dan Aplikasinya. P.T. Pradnya Paramita, Jakarta. Edisi kedua. ISBN 979-408-377-1. 268 pp.

Abidin, H.Z., A. Jones, J. Kahar (1995). Survei Dengan GPS. P.T. Pradnya Paramita, Jakarta. ISBN 979-408-380-1. 153 pp.

DPPT (Dinas Pemetaan dan Pengukuran Tanah) Jakarta (2000). Pemetaan di DKI Jakarta, Sejarah dan Prospek Pengembangannya. DPPT Jakarta, 86 hal. 